\title{
A guia-interpretação no processo de inclusão do indivíduo com surdocegueira
}

\section{The guide-interpretation in guy inclusion process of deafblind person}

\author{
Wolney Gomes Almeida*
}

\begin{abstract}
RESUMO
Refletir sobre a pessoa com surdocegueira e, sobretudo, sobre o atendimento direcionado ao surdocego, no contexto socioeducacional, constitui-se numa necessidade acadêmica, seja sobre a produção de conhecimentos teóricos, seja sobre as intervenções práticas. Essa problemática configura os caminhos percorridos pela presente tese de doutorado, a fim de investigar a atuação do profissional guia-intérprete no atendimento às pessoas com surdocegueira na cidade de Salvador, capital da Bahia; identificando os procedimentos de intervenção utilizados pelos profissionais, a partir das práticas comunicativas com surdocegos e caracterizando os fatores e os aspectos que interferem em sua atuação profissional como mediadores para a socialização do surdocego. Este trabalho pauta suas reflexões a partir das contribuições teóricas sociointeracionistas apresentadas por Vygotsky, compreendendo-se que a relação do sujeito surdocego com o meio constitui fator essencial para o desenvolvimento dos indivíduos. A escolha metodológica define um caminho para o estudo de caso e, a partir dos instrumentos de investigação definidos pela entrevista e pela observação direta, permite a análise sobre a falta de informações e de conhecimentos específicos sobre a deficiência como um fator determinante para o surgimento de barreiras de ordem estrutural, programática, atitudinal, arquitetônica que atingem tanto a qualidade dos serviços prestados ao surdocego quanto a realidade social deste indivíduo, constituindo assim uma realidade excludente e de segregação.
\end{abstract}

Palavras-chave: Formação profissional. Inclusão socioeducacional. Guiaintérprete. Mediação. Surdocegueira.

DOI: $10.1590 / 0104-4060.49000$

* Universidade Estadual de Santa Cruz. Ilhéus, Bahia, Brasil. Campus Soane Nazaré de Andrade, km 16, Rodovia Ilhéus-Itabuna. CEP: 45662-000. E-mail: wolney_22@yahoo.com.br 


\begin{abstract}
Reflecting about the person with deaf-blindness and, above all, the treatment given to the deaf-blind in the social and educational context is an academic need, either in production of theoretical knowledge or in practical interventions. This problematic sets the paths taken by this article, in order to investigate the importance of professional practice of the guideinterpreter in helping people with deaf-blindness, from their communicative practices with the deaf-blind and characterizing which factors and aspects interfere with their professional activities as mediators for the socialization of the deaf-blind. This work bases its reflections on the socio-interactionist theoretical contributions, understanding that the relationship of the deafblind subject with the environment is an essential factor for the development of individuals. The bibliographical research enables analysis of the lack of information and expertise on disability as a factor in the emergence of structural, programmatic, attitudinal and architectural barriers, which affect both the quality of treatment to the deaf-blind, as well as the social reality of these individuals, thus providing a reality of exclusion and segregation.
\end{abstract}

Keywords: Guide-interpreter. Educational inclusion. Social inclusion. Mediation. Deaf-blindness.

\title{
Introdução
}

A reflexão sobre a pessoa com deficiência na perspectiva da diferença e da diversidade tem se tornado palco de discussões em diversos espaços, tanto no âmbito educacional quanto nos diversos setores da sociedade que contemplem a acessibilidade, o direito e o desenvolvimento social de todos os indivíduos, tenham eles alguma deficiência ou não.

Nesse contexto, destaca-se a grande necessidade de ampliar o conhecimento e as discussões a respeito da pessoa com surdocegueira, partindo da própria problematização sobre o que é esta deficiência, como ela se constitui na formação do indivíduo inserido na sociedade, quais relações se dão para seu desenvolvimento e quais os espaços de sua inserção. Nesse sentido, considera-se assim as suas especificidades como a aquisição linguística no que se refere ao seu desenvolvimento cognitivo e motor, as formas de comunicação que podem desenvolver e, sobretudo, perante a realidade da atuação de profissionais especializados que atendam às necessidades do indivíduo surdocego.

Dessa forma, o conhecimento sobre o sujeito com surdocegueira e as singularidades de seu desenvolvimento tornam-se elementos básicos para que 
a inserção social, de fato inclusiva, constitua-se de forma efetiva na realidade da educação e da sociabilidade.

Por isso, o objetivo desta pesquisa é analisar a atuação do profissional guia-intérprete no atendimento aos alunos com surdocegueira na cidade de Salvador, capital da Bahia. Com isso, justificamos que o objeto de estudo, nesta pesquisa, ao se tratar da atuação profissional de guia-intérpretes e sua relação intrínseca no processo de formação como fio condutor para um real atendimento às necessidades das pessoas com surdocegueira, não observará as instituições onde procede esta atuação, visto que se trata de uma atuação profissional, na maioria das vezes, autônoma e que nem todos os sujeitos investigados possuem vínculo empregatício, como nos casos daqueles que atuam em eventos e em ambientes religiosos.

É a partir da contribuição das bases teóricas sociointeracionistas (VYGOTSKY, 2007) que este trabalho pautará suas reflexões, compreendendo que a relação do sujeito surdocego com o meio constitui fator essencial para o desenvolvimento dos indivíduos, reforçando a compreensão de que nesta relação, a presença de um mediador se constitui como o elo metodológico para as práticas educativas no atendimento aos sujeitos surdocegos. Nessa mediação é que se compreendem os processos comunicativos como indispensáveis em qualquer dinâmica de ensino-aprendizagem e que sua ausência, parcial ou total, provoca uma "privação de informações".

Portanto, o interesse em contribuir para a produção de conhecimento nesta área específica da deficiência "surdocegueira" alia-se ao desejo de estabelecer relações que contribuam para o processo de desenvolvimento social, cognitivo, cultural, no atendimento educacional e na formação de indivíduos que atuem na sociedade, encontrando cada vez menos barreiras para sua constituição como cidadãos.

Assim esta pesquisa permite a compreensão também sobre a amplitude deste objeto, a partir das novas inquietações surgidas e dos novos estudos que daqui podem surgir para a produção de conhecimentos outros e, sobretudo, de novas práticas que permitam o rompimento de paradigmas e de mudanças na sociedade em que vivemos.

\section{Um olhar sociointeracionista para a inclusão da pessoa com surdocegueira}

Vygotsky foi um dos pesquisadores que se preocupou com os aspectos que envolvem a construção do sujeito a partir de experiências adquiridas por meio da 
interação com o outro. Em sua época, foi considerado uma das poucas pessoas que se debruçava a investigar temas relacionados à Educação Especial e assim proporcionar a reflexão sobre o processo de aprendizagem que se estabelece no indivíduo com deficiência. Realizando um contraponto analítico entre a deficiência e os padrões de normalidade sobre a aprendizagem, debruçando-se sobre a deficiência sensorial e intelectual, Vygotsky, na visão de Monteiro (1998, p. 73),

[...] focalizou o desenvolvimento do portador de deficiência a partir dos pressupostos gerais que orientavam a sua concepção do desenvolvimento de pessoas consideradas normais; desses pressupostos ele destacou os aspectos qualitativamente diversos desses indivíduos, em virtude, não apenas de suas diferenças orgânicas, mas das peculiaridades de suas relações sociais - fatores que fazem com que o portador de deficiência seja, não simplesmente menos desenvolvido em determinados aspectos que seus companheiros, mas um sujeito que se desenvolve de uma outra maneira.

Para o autor, as pessoas com deficiência podem se beneficiar do processo de aprendizagem, bem como as pessoas que não apresentam nenhuma deficiência, desde que sejam corretamente estimuladas e o ambiente educacional seja receptivo para que se apropriem de recursos educacionais adequados para que possam assimilar grande parte dos conhecimentos. Esse argumento se sustenta, fundamentalmente, ao dizer que a aprendizagem é essencialmente social e que, nas apropriações de habilidades e conhecimentos socialmente disponíveis, as funções psicológicas humanas se constroem.

Vygotsky propôs algumas assertivas sobre a educação e o desenvolvimento desses indivíduos, sobre as quais ainda se fundamentam como bases epistemológicas nos dias atuais, mesmo 70 anos após concluídos seus estudos e escritos. No livro Fundamentos de Defectologia (1997), o autor apontou as dificuldades, as características, as peculiaridades do desenvolvimento e as situações socioeducacionais das pessoas chamadas por ele de "anormais".

Ao ser analisado o termo "anormais", pode-se perceber que Vygotsky não negligenciava a dificuldade das pessoas com deficiência ante as analogias ou retóricas substanciais, até mesmo devido à época, mas demarca em seus estudos a responsabilidade com o desenvolvimento real dos indivíduos. Sendo assim, é importante descrever as principais contribuições desses escritos para a Educação Especial.

Um aspecto a ser considerado, quanto à demarcação de seus estudos, é que as crianças com deficiências percorrem caminhos que as levam a enfrentar 
obstáculos, denominados de entorno. Esses desvios se configuram pelo desenvolvimento de estímulos do ambiente e aparecem quando as atividades naturais do processo de desenvolvimento não são possíveis de serem realizadas através dos mecanismos também considerados naturais para o ser humano.

Dessa forma, o meio tem importância fundamental no desenvolvimento da criança com deficiência, sendo que possibilitará a ela subsídios ou mecanismos de compensação sobre suas dificuldades, do mesmo modo que irá impor limites a serem transpostos. Esses limites contribuirão para que a criança construa suas próprias alternativas em busca de equilíbrio sobre as funções adaptativas para a convivência com o meio social.

As limitações que são impostas são determinantes para a desigualdade entre os indivíduos e para o fortalecimento do sentimento de inferioridade e inoperância. É a partir desse sentimento que muitos desenvolvem artifícios ou mecanismos de compensação e supercompensação quanto às reações sobre o estado de inferioridade e de diferença. Daí imprime-se a importância sobre os estímulos dados às crianças com deficiências para que as barreiras enfrentadas, seja no campo sensorial, seja no intelectual, tornem-se estímulos para o seu próprio desenvolvimento.

Considerando todo o processo de integração social e todos os estereótipos constituídos sobre a diferença, a sociedade demarca a partir das relações de poder, a constituição da normalidade e consequentemente da sujeição sobre aqueles que se encontram na condição de deficiência. O olhar sociointeracionista, para Vygotsky, contempla a construção de oportunidades para o indivíduo estar inserido ao meio, desde que o meio se adapte às condições demarcadas pela diferença.

Vygotsky (1995), ao tratar de forma sistemática sobre o desenvolvimento psicológico do ser humano, atribuía, de modo sociointeracionista, uma grande importância ao domínio da cultura nesse processo, compreendendo assim a existência das relações em cultura e desenvolvimento que reflete diretamente no contexto pedagógico.

É sobre essa valorização social que o autor compreende que o biológico e o orgânico se relacionam diretamente com a constituição cultural do indivíduo, estabelecendo a formação sociobiológica de cada sujeito. Contudo, para as pessoas com deficiências e com alterações sobre os aspectos biológicos e orgânicos, os fatores culturais sofrem implicações em sua própria constituição na construção de sujeito.

Nesse sentido, Vygotsky (1997, p. 12-13) esclareceu que

La especificidad de la estructura orgánica y psicológica, el tipo de desarrollo y de personalidad, y no las proporciones cuantitativas distinguen al 
niño débil mental del normal. [...] ahora la defectologia, declara la debilidad mental infantil como una variedad especial, como un tipo especial de desarrollo, y no como una variante cuantitativa del tipo normal. Se trata de formas orgánicas diferentes, a semejanza del renacuajo y la rana. ${ }^{1}$

A criança sem deficiência cumpre o desenvolvimento cultural alcançando o nível intelectual do homem culto, e a criança com deficiência não completa o desenvolvimento cultural devido a sua deficiência orgânica limitá-la. Assim, se o meio não possibilitar os estímulos e as adaptações necessários, o desenvolvimento cultural desse indivíduo será comprometido.

Vygotsky (1997) também apresentou seus estudos referentes à área da surdez e da deficiência visual, mais precisamente a discussão de que essas deficiências não são simplesmente caracterizadas pela ausência dos sentidos da audição e da visão, respectivamente. São sentidos considerados sociais, pois atuam como mediadores entre indivíduo e sociedade, com importante função na comunicação e na interação das pessoas.

É fundamental para a compreensão da deficiência que sejam levadas em conta que a cegueira e a surdez são o estado normal e não patológico do indivíduo. O mesmo que Skliar (2002) considera sobre a invenção da surdez, em que a ideia de um sujeito surdo, incapaz de desenvolver-se, foi construído pela própria sociedade, pelos saberes médicos e pelas práticas de normalização impostas aos surdos. Assim os sujeitos com e sem deficiências necessitam de vivências significativas, experimentar e brincar para desenvolver-se. Desse modo será justamente na escola que a pessoa com deficiência intensificará o uso de instrumentos psicológicos. Ela passará a ter consciência do significado da linguagem, e o desenvolvimento depende dessas descobertas, pois a criança se desenvolve à medida que aprende.

Vygotsky descreve a escola como sendo o próprio lugar da psicologia, porque nela é que se realizam sistematicamente e intencionalmente as construções e a gênese das funções psicológicas superiores. Essas funções são o resultado da influência cultural na aprendizagem e no desenvolvimento e só podem ser explicadas através de sua história.

Ao refletir sobre tais concepções a respeito da importância da socialização no processo de desenvolvimento e aprendizagem do educando, questiona-se

1 A especificidade da estrutura orgânica e psicológica, o tipo de desenvolvimento e de personalidade, e as proporções quantitativas distinguem a criança com retardo mental daquela normal. [...]. Agora, a defectologia diz sobre a fraqueza mental das crianças como uma variedade especial, como um tipo especial de desenvolvimento, e não como uma variante quantitativa do tipo normal. Trata-se de formas orgânicas diferentes, como o do girino e do sapo. [Traduzido pelo pesquisador]. 
sobre o que se refere às responsabilidades dos espaços escolares e não escolares em se adaptarem para atender a todas as pessoas, independentemente de suas (d)eficiências. Especialmente as pessoas com deficiência, cujas escolas não podem educar efetivamente sem apoio adicional, sem o papel indispensável que os professores e os colegas desempenham ao mediar o mundo para o aluno incluído.

\section{O guia-intérprete como mediador no processo de inclusão: desenhando o método e a pesquisa}

Transitando por diferentes disciplinas e áreas de conhecimento das ciências humanas, como a Sociologia, a Antropologia, o Serviço Social, a Educação e outras, o método remonta os traços presentes em todo fazer teórico, acadêmico e normativo para o desenvolvimento do(s) olhar(es) de cada pesquisador.

Sob olhares e caminhos passíveis e possíveis a se percorrer, a presente pesquisa se propõe a uma abertura de enfrentamentos e de questionamentos que, dirigidos por uma inquietação investigativa, pretende responder e, ao mesmo tempo, suscitar novos questionamentos sobre a problemática norteadora, tecendo assim um constructo de saberes e de conhecimentos com o propósito de contribuir para o conhecimento teórico, mas, sobretudo, para o fazer prático sobre o qual a temática abordada se insere.

Para construir esse caminho metodológico, a escolha do estudo de caso, de caráter descritivo, apresenta-se por favorecer a aproximação entre o pesquisador e o campo de investigação. Esse método se configura pela necessidade de investigar um fenômeno contemporâneo dentro do contexto real. Para esta pesquisa, foram contempladas as instituições de ensino da rede pública e privada e também as associações de atendimento às pessoas com surdocegueira na cidade de Salvador.

Para estabelecer os critérios de inclusão/exclusão sobre a escolha dos sujeitos da pesquisa e para atender à problemática levantada, foram selecionadas uma das seguintes características que melhor definem o perfil desta investigação: a) que estejam inseridos em instituições de ensino na rede pública ou particular na cidade de Salvador; ou b) que estejam inseridos em associações ou demais instituições de atendimento às pessoas surdocegas na cidade de Salvador; ou c) que tenham passado pelo curso de formação de guias-intérpretes oferecidos por instituições especializadas. Foram selecionados onze guias-intérpretes, levando em consideração a aceitação de cada indivíduo, a fim de contribuir de 
maneira representativa ante o grupo de profissionais que atuam no atendimento ao surdocego.

É necessário esclarecer que não tivemos como foco de discussão analisar os locais onde cada um dos guia-intérpretes atua na cidade de Salvador, visto que são profissionais autônomos, e nem todos possuem vínculo empregatício nas instituições ou nas situações eventuais de atuação como guia-intérpretes. Dessa forma, a pluralidade dos ambientes, onde os sujeitos pesquisados atuam, não reflete, nesta pesquisa, o objetivo principal para análise de suas atuações como profissionais.

A elaboração da entrevista apresenta, em primeira instância, elementos exploratório-descritivos que identificam o perfil dos profissionais guias-intérpretes. Também foram considerados os elementos investigativos que contemplam a formação específica de cada profissional para atuarem no campo da guia-interpretação.

A análise dos dados foi estabelecida de forma interpretativa a fim de compreender o fenômeno estudado, assumindo, em concordância com Myers e Wildemuth (1993) que a realidade é subjetiva e socialmente construída.

Por fim, o caminho metodológico traçado, aqui apresentado, compreende o desenvolvimento de olhares e percursos do pesquisador no intuito de conhecer a realidade da inclusão da pessoa com surdocegueira, com o direcionamento desse olhar sobre a atuação do profissional guia-intérprete, analisando, sobretudo, esta atuação, reconhecendo a necessidade da formação profissional para que o atendimento educacional ao surdocego se configure a partir de práticas inclusivas efetivamente de qualidade.

\section{Caracterização dos sujeitos}

Participaram da pesquisa onze profissionais, sendo quatro do sexo masculino e sete do sexo feminino. A faixa etária estabelecida apresenta indivíduos com idade variando entre 28 e 39 anos. Como critério de inclusão/exclusão, foram contatados apenas aqueles sujeitos que já desenvolveram ou desenvolvem atendimento às pessoas surdocegas ou que passaram por curso de formação específico na área da guia-interpretação.

A seguir, o Quadro 1 estabelece o desenho desse perfil biossocial e profissional dos sujeitos. Para atender ao critério de garantia e de manutenção do sigilo e privacidade dos participantes da pesquisa, usaremos o modelo de identificação alfanumérico GI-1, GI-2 e GI-3 para identificar cada um dos onze guias-intérpretes participantes. 
QUADRO 1 - PERFIL BIOSSOCIAL E PROFISSIONAL DOS SUJEITOS DA PESQUISA

\begin{tabular}{|l|c|c|c|c|c|}
\hline SUJEITO & $\begin{array}{c}\text { Faixa } \\
\text { etária }\end{array}$ & Nível de formação & $\begin{array}{c}\text { Formação } \\
\text { superior }\end{array}$ & Local de atuação & $\begin{array}{c}\text { Tempo de } \\
\text { atuação } \\
\text { (anos) }\end{array}$ \\
\hline GI-1 & 28 & superior & Letras/Libras & eventos/ igrejas & 4 \\
\hline GI-2 & 31 & superior & Letras/Libras & eventos/ igrejas & 4 \\
\hline GI-3 & 32 & superior & $\begin{array}{c}\text { Letras/Libras; } \\
\text { História. }\end{array}$ & eventos / escolas & 10 \\
\hline GI-4 & 32 & superior & Letras/Libras & igrejas & 8 \\
\hline GI-5 & 35 & superior & $\begin{array}{c}\text { Letras/Libras; } \\
\text { Pedagogia. }\end{array}$ & igrejas & menos de 1 \\
\hline GI-6 & 36 & superior (em curso) & Pedagogia & eventos & 6 \\
\hline GI-7 & 36 & superior & Pedagogia & escolas & 9 \\
\hline GI-8 & 37 & médio & ------- & escolas / igrejas & 5 \\
\hline GI-9 & 38 & superior (em curso) & Letras/Libras & escolas & menos de 1 \\
\hline GI-10 & 38 & superior & Letras & igrejas & 5 \\
\hline GI-11 & 39 & superior & Letras/Libras & eventos & 1 \\
\hline
\end{tabular}

FONTE: Entrevista com os sujeitos da pesquisa.

A característica biossocial dos entrevistados, ainda que não determine diretamente o caráter de qualificação para atuação no campo da guia-interpretação e do atendimento à pessoa surdocega, representa aqui a faixa etária dos sujeitos, como um reflexo dos novos olhares para a educação de pessoas com deficiências e, principalmente, sobre o próprio conhecimento a respeito da surdocegueira como deficiência. No quesito "escolaridade", não foram estabelecidos critérios de inclusão/exclusão a fim de contemplar um maior número da amostra e de poder analisar a importância da formação desses indivíduos para sua atuação profissional. Como resultado, observa-se apenas um sujeito com ensino médio concluído, dois estão cursando formação em nível superior e oito possuem pelo menos um curso de graduação.

Importante observar que todos os guias-intérpretes que possuem nível superior, apresentam essa formação no campo da Educação, seja em Pedagogia, seja em Letras, com habilitação em Libras. Esse fator é imprescindível para que seja analisado o nível de conhecimento específico no campo da Educação Especial/ inclusiva, uma vez que, principalmente, o curso de licenciatura ou bacharelado em Letras/Libras habilita o egresso para atuação e atendimento de indivíduos surdos e também surdocegos, que sejam usuários da Língua Brasileira de Sinais 
como principal recurso para comunicação. Assim compreende-se que a maioria dos entrevistados possui uma formação inicial direcionada para o público com deficiência auditiva ou surdocegueira.

Esse perfil demonstra que a formação em nível superior em $72 \%$ dos entrevistados é um importante fator a ser considerado, uma vez que as especificidades de formação constituem a busca por uma atuação profissional com qualidade, principalmente por se tratar de uma atuação que requer conhecimentos teórico/ práticos nos campos da Educação, Comunicação, Linguagens, Sociologia e Antropologia, Saúde, associados à multidisciplinaridade das áreas de conhecimento em que esses sujeitos atuam. Tal fator se torna bastante expressivo à observação, principalmente pelo número de sujeitos graduados no curso de Letras com habilitação em Libras e em Pedagogia, bem como o expressivo número percentual (62,5\% dos graduados) de pós-graduados em Libras e em Tradução/Interpretação em Libras.

Para Maia, no processo de inclusão da pessoa com surdocegueira, é "necessário levar em consideração a importância do profissional guia-intérprete e ou do instrutor-mediador, pois será a conexão da pessoa com surdocegueira com o mundo que o rodeia" (MAIA, 2005, p. 107).

Ao considerar que o profissional guia-intérprete é aquele que serve de canal de comunicação e visão entre a pessoa com surdocegueira e o meio no qual ela está interagindo, este profissional deve apresentar algumas habilidades essenciais para que consiga transmitir todas as informações de modo fidedigno e compreensível à pessoa com surdocegueira. Seu trabalho basicamente consiste na transliteração ou interpretação, descrição visual e as funções de guia vidente (PETRONI, 2010). Por isso, a formação inicial e a continuada se tornam imprescindíveis para a competência dessa atuação profissional.

\section{Formação específica para atuação na área de guia-interpretação}

Para atender ao eixo proposto sobre a formação e atuação profissional dos guias-intérpretes, foi questionado aos profissionais sobre os cursos de formação realizados por eles tanto o item "capacitação na área de surdocegueira" quanto o item "capacitação na área de guia-interpretação" oferecidos por alguma instituição credenciada (por exemplo, AHIMSA, GRUPO BRASIL, ABRASC) ou qualquer outra instituição.

Essas informações, além de definir o perfil dos sujeitos desta pesquisa, estabelecem de forma clara o universo de profissionais que estão em condições 
de atuarem como guias-intérpretes e que confrontarão os dados exploratórios com os objetivos estabelecidos por esta proposta de pesquisa.

O Gráfico $1 \mathrm{a}$ seguir apresenta o referido perfil quanto à participação em cursos de capacitação em surdocegueira ou em guia-interpretação.

\section{GRÁFICO 1-CAPACITAÇÃO NA ÁREA ESPECÍFICA PARA O ATENDI- MENTO AO SURDOCEGO}

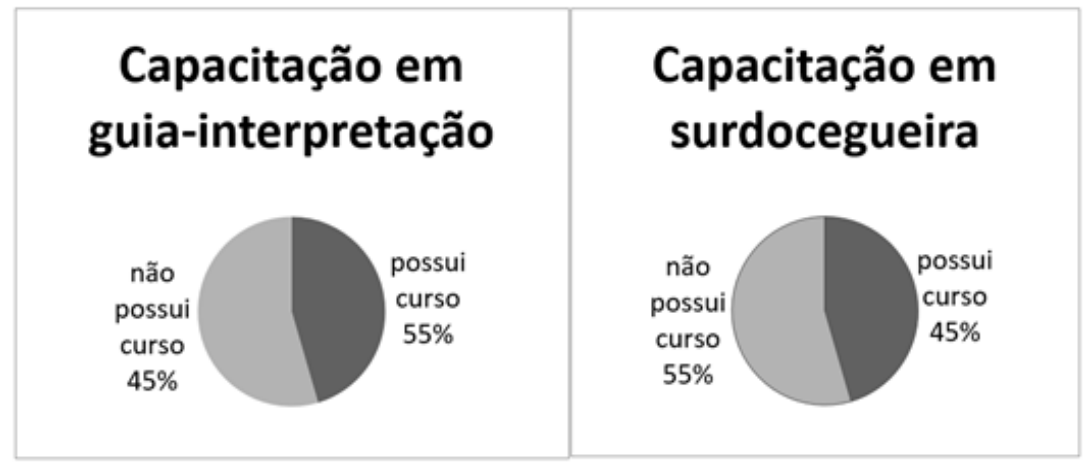

FONTE: Entrevista com os sujeitos da pesquisa.

Dos onze guias-intérpretes pesquisados, cinco (45\%) possuem curso de capacitação na área de surdocegueira e seis (55\%) não possuem nenhum curso de capacitação oferecido por instituições credenciadas. Aqueles com formação relatam que tiveram cursos realizados pelo Grupo Brasil, AHIMSA e pelo Instituto de Cegos da Bahia (ICB). Entre aqueles que não realizaram cursos credenciados, dois afirmam ter participação em minicurso e oficina sobre surdocegueira com carga horária de 4 horas em congressos realizados na Bahia.

Em relação à formação na área de guia-interpretação, seis $(55 \%)$ dos entrevistados afirmam ter realizado curso de formação ministrado pelo Grupo Brasil, Instituto de Cegos da Bahia, ABRASC e AHIMSA. Cinco (45\%) dos entrevistados disseram não ter passado por nenhum curso de formação na área de guia-interpretação.

A partir do curso de formação de guias-intérpretes, as pessoas que já atuavam como tal foram tomando consciência de seu papel e buscaram a aproximação com a formação para melhor se capacitarem. A busca de formação e identidade do guia-intérprete acontece, de modo geral, isoladamente. À medida que esse profissional começa a participar de eventos e congressos, além de sua inserção na luta de classe pela fundação das associações, inicia-se um fortalecimento profissional, um convívio maior com os intérpretes de Língua 
de Sinais e uma parceria com a associação, incluindo-se, inclusive, a palavra "guia-intérprete" também no nome das associações e dos eventos relacionados ao tema da interpretação.

Quanto ao tempo de experiência no atendimento à pessoa surdocega, cada um dos entrevistados apresenta um período diferenciado, observando que nove deles já atuam como intérpretes de Língua Brasileira de Sinais com pessoas surdas, e, durante este período, realizaram sua formação complementar na área da guia-interpretação e surdocegueira ou, empiricamente, passaram por experiências profissionais nesse atendimento, como já apresentado no eixo anterior.

As experiências profissionais vivenciadas pelos entrevistados estão inseridas no tempo de experiência como tradutores/intérpretes da Língua Brasileira de Sinais, uma vez que, dos onze entrevistados, oito já exerciam atendimento com pessoas surdas antes de atuarem ou buscarem capacitação para o atendimento ao surdocego.

Apenas dois declaram apresentar menos de um ano de atuação no atendimento às pessoas surdocegas, e oito possuem entre quatro a dez anos de experiência, o que denotaria, hipoteticamente, um grau de maturação importante para que a atuação profissional acontecesse. Contudo, a pesquisa demonstra que o tempo de experiência, necessariamente, não reflete a maturação correspondente ao tempo de atuação, quando considerada a porcentagem dos que apresentam cursos de capacitação ou de formação na área da surdocegueira e/ ou da guia-interpretação, e, principalmente, por não encontrarem núcleos de apoio, associações específicas para surdocegos e instituições especializadas para o atendimento a surdocegueira na cidade de Salvador.

Considerando que a escola é um importante ambiente que potencializa o desenvolvimento cognitivo, social e cultural dos indivíduos, uma vez que as relações estabelecidas entre os educandos e todo o contexto em sua volta estão propícias para tal construção individual e coletiva, argumenta-se que o espaço escolar para o desenvolvimento humano da pessoa surdocega deve ser tratado como espaço fundamental de acesso e, consequentemente, permanência desse público nos espaços escolares. Defende-se aqui a real necessidade do guia-intérprete para que o surdocego tenha suas especificidades de comunicação atendidas, e, sobretudo, as condições para desenvolverem-se em seu pleno estado de direito.

Por isso, Plazas (2009, p. 34) esclarece que:

El guía-interprete además de ser un facilitador linguístico y cultural entre usuários de diferentes lenguas o sistemas comunicativos, ayuda a conectar a la persona com surdoceguera com su entorno, actuando como sus ojos 
e sus oidos. De esta manera él promueve la integración y participación independente de la persona sordociega em su entorno. ${ }^{2}$

Recorre-se a Souza (2007, p. 159) ao argumentar que a ação do intérprete, e aqui se contextualiza também a ação do guia-intérprete, é antes de tudo a de um educador. $\mathrm{O}$ autor defende que a ordem como o processo tradutório se constitui, muitas vezes é reduzida tecnicamente, e é quase impossível de ser realizada nesse contexto. A ação de interpretar vai além, e é impossível permanecer neutro diante deste cenário de subjetividades da comunicação entre os indivíduos. Para amenizar os problemas neste contexto de tradução, o processo de formação profissional é essencial.

De forma analítica, a atuação do guia-intérprete tem se constituído a partir da necessidade de formação e de capacitação. Através da percepção dos entrevistados, a falta de estrutura dos espaços escolares e não escolares, a falta de instituições de atendimento especializado ao surdocego e de órgãos que possam tanto regulamentar as ações específicas quanto fiscalizar o atendimento tornam-se fatores que comprometem a acessibilidade das pessoas com surdocegueira na sociedade, fortalecendo assim a realidade excludente desses indivíduos.

\section{Considerações finais}

Retomando o objetivo desta pesquisa de analisar a atuação dos profissionais guias-intérpretes no atendimento às pessoas com surdocegueira na cidade de Salvador, pôde-se compreender o grande impacto que este trabalho tem sobre os ambientes escolares e não escolares que atendem aos surdocegos e, sobretudo, sobre a prática desenvolvida nesse atendimento.

Compreender o atendimento socioeducacional a partir da perspectiva inclusiva, revela cada vez mais uma prática fundamental para o desenvolvimento de aprendizado das pessoas com deficiências. Ao se tratar de pessoas com surdocegueira, essa perspectiva se torna ainda mais complexa perante o grande desconhecimento sobre a deficiência, e, principalmente, ante a falta de

2 O Guia-intérprete, além de ser um facilitador linguístico e cultural entre os usuários de línguas diferentes ou sistemas comunicativos, ajuda a conectar a pessoa com surdocegueira com o que está em sua volta, atuando como seus olhos e seus ouvidos. Desta maneira, ele promove a integração e participação independente da pessoa surdocega em seu universo. [Tradução do pesquisador]. 
profissionais com formação para a atuação específica no contexto da educação dos indivíduos surdocegos.

Percebe-se que a formação acadêmica e continuada dos profissionais que, na cidade de Salvador, atuam na área da surdocegueira, ainda apresentam lacunas, uma vez que a formação básica nesta área ainda não se estabeleceu nos cursos de graduação e de pós-graduação, principalmente quando verificado que nenhum dos entrevistados apresenta esta formação em nível superior ou em nível de pós-graduação, mas, apenas em cursos de capacitação ou em minicursos e oficinas realizados em eventos que abordam a temática.

Assim os serviços de atendimento existentes ainda estão distantes de promover a real inclusão com qualidade da pessoa com surdocegueira, haja vista inúmeras dificuldades encontradas no processo educativo, principalmente no que concerne às adaptações no espaço físico-estrutural e na escassez de recursos humanos capacitados para esse atendimento.

De modo geral, constata-se, por meio dos relatos dos participantes, a necessidade de formação/capacitação inicial e continuada tanto do profissional guia-intérprete quanto do professor especialista e do professor do ensino regular. Essa formação deve ocorrer de modo contínuo ao longo da carreira funcional do profissional, uma vez que, considerando o contexto histórico sobre a deficiência, o atendimento especializado ao surdocego se constitui numa mudança de paradigma dentro do próprio contexto da inclusão, em virtude dos conhecimentos e metodologias desse atendimento estarem em processo de construção e formatações não apenas na cidade de Salvador, como em todo contexto nacional.

A grande necessidade de formação de guias-intérpretes reconhece a fragilidade da educação inclusiva para os surdocegos e para todo o processo de inclusão social aqui especificado, visto que o número de profissionais capacitados não contempla a todas as especificidades do atendimento aos sujeitos, compreendendo ainda que a ausência desses indivíduos nos espaços escolares é reflexo também da fragilidade do próprio sistema. Assim entende-se que desempenhar a função de guia-intérprete é considerado um trabalho importante, prazeroso e emocionante, ao mesmo tempo que proporciona ao indivíduo surdocego a retomada de suas possibilidades e de seu papel na sociedade.

Para muitos surdocegos, receber o apoio de guias-intérpretes significa dizer que este terá a oportunidade de se comunicar com alguém que conheça seu modelo de comunicação. Por isso atuar neste campo profissional significa estabelecer uma relação de comunicação não apenas entre o indivíduo com o profissional, mas também deste indivíduo com o mundo que o cerca. 


\section{REFERÊNCIAS}

GRUPO BRASIL de apoio ao surdocego e ao deficiente múltiplo sensorial. Folheto Informativo sobre surdocegueira. São Paulo, 2003.

MAIA, S. R. A Educação do Surdocego: diretrizes básicas para pessoas não especializadas. 2004.93 f. Dissertação (Mestrado em Distúrbio do Desenvolvimento) - Universidade Presbiteriana Mackenzie, São Paulo. 2005.

MONTEIRO, M. A educação especial na perspectiva de Vygotsky. In: ASSUNÇÃO, M. Vygotsky: um século depois. Juiz de Fora: EDUFJF, 1998.

MYERS, M.; WILDEMUTH, B M. Post-positivist research: two examples of methodological pluralism. Library Quarterly, v. 63, n. 4, p. 450-468, oct. 1993.

PETRONI, K. Deaf-blind Interpreting: Building on What You Already Know. Cadernos de Tradução, v. 2, n. 26, p. 237-273, 2010. Disponível em: <http://www.periodicos.ufsc. br/index.php/traducao/article/viewArticle/15716>. Acesso em: 04 maio 2015.

PLAZAS, M. M. R. Papel del guia-interprete. In: CONGRESSO NACIONAL DE LA SITUACION DEL SORDO EM COLOMBIA, 6., ECUENTRO LATINO AMERICANO DE INTERPRETES E GUIAS-INTERPRETES DE LENGUA DE SENAS, 1., 7,8,9 y 10 de Julio de 2009 Bogotá-Colômbia. Anales...

SKLIAR, C. A surdez: um olhar sobre as diferenças. Porto Alegre: Dimensão, 2002.

SOUZA, M. M. P. de. Voando com gaivotas: um estudo das interações na educação de surdos. Dissertação (Mestrado em Educação Brasileira) - Pró-Reitoria de Pesquisa e Pós-Graduação, Fortaleza, UFC. 2007.

VYGOTSKY, L. S. Obras completas. Fundamentos de defectología. Havana: Editorial Pueblo y Educación, 1995.

VYGOTSKY, L. S. Obras escogidas. Tomo V. Fundamentos de defectologia. Madrid: Portugal: Visor, 1997.

VYGOTSKY, L. S. A formação social da mente. São Paulo: Martins Fontes, 2007.

Texto recebido em 25 de outubro de 2016. Texto aprovado em 09 de fevereiro de 2017. 
